$7-2004$

\title{
An investigation of social influence: Explaining the effect of group discussion on consensus in auditors' ethical reasoning
}

\author{
Linda Thorne \\ Dawn W. Massey \\ Fairfield University, dmassey@fairfield.edu \\ Joanne Jones
}

Follow this and additional works at: https://digitalcommons.fairfield.edu/business-facultypubs Copyright 2004 Philosophy Documentation Center

\section{Peer Reviewed}

\section{Repository Citation}

Thorne, Linda; Massey, Dawn W.; and Jones, Joanne, "An investigation of social influence: Explaining the effect of group discussion on consensus in auditors' ethical reasoning" (2004). Business Faculty Publications. 93.

https://digitalcommons.fairfield.edu/business-facultypubs/93

\section{Published Citation}

Thorne, Linda, Dawn Massey and Joanne Jones. 2004. "An investigation of social influence: Explaining the effect of group discussion on consensus in auditors' ethical reasoning." Business Ethics Quarterly, Volume 14, Issue 3 (July), pp. 525-551.

This item has been accepted for inclusion in DigitalCommons@Fairfield by an authorized administrator of DigitalCommons@Fairfield. It is brought to you by DigitalCommons@Fairfield with permission from the rightsholder(s) and is protected by copyright and/or related rights. You are free to use this item in any way that is permitted by the copyright and related rights legislation that applies to your use. For other uses, you need to obtain permission from the rights-holder(s) directly, unless additional rights are indicated by a Creative Commons license in the record and/or on the work itself. For more information, please contact digitalcommons@fairfield.edu. 


\title{
AN INVESTIGATION OF SOCIAL INFLUENCE: EXPLAINING THE EFFECT OF GROUP DISCUSSION ON CONSENSUS IN AUDITORS’ ETHICAL REASONING
}

\author{
Linda Thorne \\ Schulich School of Business \\ York University \\ 4700 Keele Street \\ North York, Ontario \\ M3J 1P3 \\ Canada \\ Phone: 416-736-5066 \\ Fax: 416-736-5762 \\ E-mail: 1thorne@ssb.yorku.ca
}

Dawn W. Massey

Charles F. Dolan School of Business

Fairfield University

1073 North Benson Road

Fairfield, CT 06824

Phone: $203 / 254-4000 \times 2844$

Fax: 203/254-4105

E-mail: $\underline{\text { dmassey@mail.fairfield.edu }}$

Joanne Jones

Schulich School of Business

York University

4700 Keele Street

North York, Ontario

M3J 1P3

Canada

Phone: 416-736-5066

Fax: 416-736-5762

E-mail: jjones@ssb.yorku.ca

This paper has previously been presented at the 1998 CAAA conference and the 1999 AAA audit conference. Appreciation is extended to Janne Chung, John Friedlan, Irene Gordon, Dennis Hanno, Kathryn Kadous, Susan McCracken, Paul Roy, Theresa Libby and the several anonymous reviewers who provided valuable comments that resulted in substantial revisions to earlier drafts of this paper. The financial support York-CGA Research Program is gratefully acknowledged. 


\title{
AN INVESTIGATION OF SOCIAL INFLUENCE: EXPLAINING THE EFFECT OF GROUP DISCUSSION ON CONSENSUS IN AUDITORS' ETHICAL REASONING
}

\begin{abstract}
This study introduces Moscovici's (1976, 1985) model of social influence to the accounting research domain, and uses an experiment to assess whether his theory explains how different types of discussion affects consensus in auditors' ethical reasoning. Moscovici's theory proposes three modalities of influence to describe how consensus is achieved following discussion: conformity, innovation and normalization. Conformity describes the situation where individuals in the minority (e.g., auditors that do not accept the dominant view) accede to the majority (e.g., auditors that hold the dominant view) as a result of group discussion. Innovation describes the situation where individuals in the majority accede to the minority. Normalization describes the situation where there is reciprocal influence.

We find that conformity occurs when auditors are asked to prescriptively discuss what ideally "should" be the resolution to an ethical dilemma. Normalization occurs when auditors are asked to deliberatively discuss what realistically would be the resolution to an ethical dilemma. The results of this study suggest that prescriptive discussion of an ethical dilemma encourages auditor groups to strive to find the best response to a moral dilemma if it is represented by the majority view. In contrast, deliberative discussion of an ethical dilemma may encourage the elimination of multiple viewpoints. The results of this study have important implications for understanding the social influence process that affects auditors' ethical reasoning.
\end{abstract}

Key Words: ethical reasoning, audit groups, social influence, and consensus.

Data Availability: Contact the first author. 


\section{INTRODUCTION}

Group decision-making plays a key role in most of the critical decisions made by auditors over the course of the audit (Rich, Solomon and Trotman 1997). As a result, the discussion that takes place during key meetings among the audit team or among a group of partners has a significant impact on the final outcome of many contentious ethical issues. For instance, consider the following excerpt from Arthur Andersen audit partner, Michael Jones, in his documentation of the critical meeting attended by key Andersen partners to discuss their concerns over the Enron account:

We discussed Enron's dependence on transaction execution to meet financial objectives, the fact that Enron often is creating industries and markets and transactions for which there are no specific rules, which requires significant judgment and that Enron is aggressive in its transaction structuring. We discussed consultation among the engagement team, with Houston management, practice management and the PSG [Professional Services Group] to ensure that we are not making decisions in isolation.

Ultimately, the conclusion was reached to retain Enron as a client citing that it appeared that we had the appropriate people and processes in place to serve Enron and manage our engagement risks. We discussed whether there would be a perceived independence issue solely considering our level of fees. We discussed that the concerns should not be the magnitude of fees but on the nature of fees. 
Given their concerns, one wonders how the Andersen partners arrived at their decision to retain Enron as a client. In particular, we wonder which type of social influence describes the process that occurred during this meeting. Would the outcome have been different if different individuals attended the meeting? Would the outcome have been different if the partners attempted to develop an “ideal" solution rather than a compromise?

To that end, we use Moscovici's theory of social influence to investigate the type of consensus achieved by groups of auditors following discussion of ethical dilemmas. In this paper, consensus refers to the degree to which group members modify their ethical reasoning following group discussion. Prior research investigating the effect of discussion on auditors' professional judgment has focused almost exclusively on the technical component of auditors' professional judgement and has not investigated how discussion influences auditors' professional judgment with an inherent ethical dimension. Yet, unlike technical judgments where there is a "single right answer" for auditors' judgments, multiple viewpoints are often considered acceptable for auditors' judgments of an ethical nature (Gaa 1993; Francis 1990). Consequently, the effect of discussion on auditors' ethical judgments may be quite different than the effect of discussion on judgments of a purely technical nature.

Prior research investigating auditors' ethical reasoning (e.g., Arnold, Bernardi, and Neidermeyer 1999; Bernardi and Arnold 1997; Louwers, Ponemon and Radtke 1997; Ponemon 1993; Ponemon and Gabhart 1993) has made significant inroads through the adoption of a cognitive-developmental perspective (Rest, Narvaez, Bebeau, and Thoma 1999). The cognitive-developmental perspective focuses its investigation on the ethical reasoning process that precipitates an ethical judgment. Accounting research employing the cognitive-developmental approach shows that auditors' ethical reasoning is sensitive to social influence (Lord and DeZoort 2001; Ponemon and Gabhart 1993; 
Ponemon 1992), and of particular interest to this study, also demonstrates that auditors' ethical reasoning becomes significantly revised as a result of discussion of ethical dilemmas with a group of peers (Thorne and Hartwick 2001). However, it is not yet understood to what extent auditor discussion of ethical dilemmas alleviates or eliminates the multiple viewpoints auditors may have of ethical dilemmas.

To increase our understanding of whether auditors' discussion of ethical dilemmas alleviates or eliminates their multiple viewpoints, this study uses Moscovici's (1976, 1985) theory of social influence as a basis to investigate the form of social influence that affects auditors' ethical reasoning. Moscovici's theory is particularly appropriate for examining the effect of discussion of ethical dilemmas because it considers how different views (i.e., minority and majority) persist depending upon individuals' perceptions of a "best" response. Moscovici (1985) posits that depending upon contextual factors, three possible outcomes may occur. They are: 1) conformity: convergence to the majority position by the minority; 2) innovation: the acceptance of the minority view by the majority; or, 3) normalization: revision of both the majority and minority views so that a compromise view prevails.

This study uses 180 auditors in an experiment to investigate the extent to which auditors in the majority and/or minority revise their ethical reasoning after engaging in discussion of ethical dilemmas with peers. The experiment tests hypotheses developed through the application of Moscovici's theory $(1980,1985)$ in a cognitive-developmental framework. The results show that when auditors are asked to prescriptively discuss what "should" be the resolution to an ethical dilemma, the majority view prevails (i.e., there is conformity), particularly when the majority is of higher ethical development than the minority. In contrast, when auditors are asked to deliberatively discuss what realistically would be done to resolve an ethical dilemma, both the majority and the minority revise their views (i.e., there is 
normalization). Although ethical dilemmas do not have a "single right answer", prescriptive discussion appears to evoke a search for the "best" response, which auditors appear to interpret as the view of the majority. In contrast, deliberative discussion appears to promote the "acceptability of compromise", which results in a reduction in multiple viewpoints among auditors.

Accordingly, this study contributes to our understanding of factors that affect how auditors reach consensus when considering ethical dilemmas. Besides being of interest to auditors and researchers studying auditors' ethics, these findings have important implications for those developing training programs to ensure that auditors maintain a high ethical standard in the resolution of ethical dilemmas.

\section{Ethical Reasoning: Theory and Findings}

Cognitive-developmental theory assumes that an individual's conception of morality or ethics, as indicated by his or her level of ethical development, affects the way that he or she will resolve ethical dilemmas. Individuals at higher levels of ethical development are able to make more sophisticated ethical decisions (Rest, Narvaez, Bebeau and Thoma 1999). The cognitivedevelopmental approach has been successfully used in applied research to describe the ethical decision process of auditors (Bernardi and Arnold 1997; Louwers, Ponemon and Radtke 1997; Lampe and Finn 1992). Of specific importance to this study are four accounting studies that investigate social influence and ethical reasoning: Ponemon (1990), Ponemon and Gabhart (1993), Lord and DeZoort (2001), and Thorne and Hartwick (2001). All four of the accounting studies have employed an experimental approach within a cognitive-developmental framework. Ponemon (1990) and Ponemon and Gabhart (1993) identify the importance of social influence on ethical reasoning by demonstrating that accounting students' propensity to underreport time increases when peer comparisons are available. Lord and DeZoort (2001) demonstrate the importance of the origins of 
social influence by showing that social pressure from superiors increases auditors' willingness to sign off on a materially misstated account balance; however, social pressure from peers does not.

Thorne and Hartwick (2001) use an experiment to consider the directional effect of discussion on auditors' subsequent consideration of realistic audit-specific ethical dilemmas. Auditors were asked to prescriptively discuss how an accountant ideally should resolve an ethical dilemma, or to deliberately discuss how an accountant actually would resolve an ethical dilemma. Thorne and Hartwick (2001) find that auditors' ethical reasoning scores are significantly different than control group subjects' scores after discussion and the direction of the difference in ethical reasoning scores varies according to the type of discussion with peers (i.e., prescriptive or deliberative); auditors have higher ethical reasoning scores after prescriptive discussion and lower ethical reasoning scores after deliberative discussion. Although Thorne and Hartwick (2001) identify that type of discussion (i.e., prescriptive or deliberative) may play an important role in auditors' ethical reasoning, they did not explore how discussion affects majority and minority views of an ethical dilemma. Thus, we do not yet know the extent to which auditor discussion of ethical dilemmas affects consensus, in terms of conformity, innovation or normalization.

\section{The Effect of Discussion on Auditors' Professional Judgement}

Existing audit research investigating the effect of discussion on auditors' professional judgments typically examine how discussion affects auditors' professional judgments of a technical nature (e.g., Bamber, Watson and Hill 1996; Wright 1988; Ashton 1985; Abdel-khalik, Snowball and Wragge 1983; Reckers and Schultz 1982; Schultz and Reckers 1981). This stream of accounting research applies and considers, implicitly or explicitly, hypotheses derived from the classical model of social influence (Solomon 1982, 1987). The classical model of social influence characterizes the influence of discussion on decisions (such as technical judgments) that have clear-cut answers and the majority represents the 
"right" decision. Asch $(1951,1955)$ conducted a series of experiments that compared responses from solitary individuals to responses made by individuals following others. The results of these experiments strongly affected the classical model of social influence by demonstrating that individuals' judgments generally conform to the response made by the majority. Thousands of replications and variations of Asch's experiments have established the applicability of the phenomenon of conformity for situations where decisions have clear-cut answers, across numerous contexts and under various conditions. For example, the phenomenon has been found to persist even after the subjects were removed from the social situation and even in situations where subjects were not required to expose their own position publicly (Moscovici 1985).

The courts, regulators and the audit profession typically use agreement among experts as a surrogate for "accuracy" in auditors' professional judgment when no objective criterion is available (Pincus 1990; Ashton 1985; Libby and Lewis 1982). The research studies that have investigated agreement among auditors show that auditors' judgments are more similar and more accurate after discussion than before (Arnold, Sutton, Hayne, and Smith 2000; Solomon 1987). However, for decisions that are highly interpretative in nature, empirical results (Keasey and Watson 1989; Einhorn 1974) reveal that social pressure can cause individuals to converge to a "wrong" or inferior answer when the majority is not necessarily "right". In particular, experimental evidence shows that interacting groups often agree immediately and unanimously on the conclusion advanced by the majority, which in interpretive decision settings, can often be the wrong one (Barnlund 1959).

Thus, the classical model of social influence facilitates our understanding of how discussion influences professional judgment of a technical nature where the "best" response is a single, correct response and is generally represented by those in the majority (e.g., Asch 1951, 1955). However, as 
demonstrated by the Enron situation, ethical dilemmas are generally ambiguous and a single correct response is not usually evident. This suggests that the classical model may not apply to all situations of social influence. Instead, we believe Moscovici's $(1976,1985)$ model of social influence appropriate for considering how discussion influences the multiple viewpoints held by auditors considering ethical dilemmas.

Moscovici's $(1976,1985)$ model of social influence is based on the premise that when individuals face opposing or different views, they experience conflict and try to redefine their own views in order to reduce that conflict. It is at this point that they are open to influence from others and attempt to influence others. Although Moscovici's model recognizes that social influence generally results in consensus to the majority view to end the conflict (i.e., conformity as generally described in Asch's $(1951,1955)$ experiments), in some situations the minority view was adopted by the majority or the minority view appeared to result in the majority modifying their view. Moreover, although conformity to the majority view generally leads to public change in judgment, it rarely leads to private change in judgment (Nemeth 1985). Because of these findings, Moscovici and his colleagues (e.g., Moscovici and Faucheaux 1972) began to consider contextual characteristics of the situation that may affect social influence, and identified two key characteristics associated with different types of social influence: 1) individuals' perceptions that a "best" response exists (i.e., the norms concerning objectivity versus pluralism) (Moscovici 1985); and 2) the perceived legitimacy of the majority and minority views.

Thus, Moscovici (1985) identifies three modalities of social influence: conformity, normalization, and innovation. Each modality is considered to be as fundamental as the other is; the modality of social influence depends upon the nature of the conflict and the interaction among the 
individuals. Conformity occurs when there is a search for the "best" response to a conflict and the majority view is recognized as legitimate. This is the situation that is described in Asch's $(1951,1955)$ experiments. The minority accedes to the majority and stability of the beliefs of the majority is maintained. Normalization occurs when there is a search for a reasonable solution to a conflict and it is recognized that several desirable different views may exist simultaneously. Sherif (1935) demonstrated this modality of influence by studying the averaging of beliefs through gradual compromises and successive stabilization. Innovation occurs when there is a search for the "best" response to a conflict and the minority view is recognized as legitimate. In this case, the minority is considered to be legitimate because for some reason there is a desire for novelty in the resolution of the conflict (Levine and Russo 1987).

\section{Prescriptive Discussion, the Norm of Objectivity, and Conformity}

In our experiment, we envision that the type of discussion sets the norms of the situation. Prescriptive discussion involves individuals exchanging views of what ideally should be done to resolve a particular ethical dilemma (Kohlberg 1958). The cognitive-developmental perspective advocates that the prescriptive response is the "ideal" or most desirable ethical response (Rest, Narvaez, Bebeau and Thoma 1999). Moscovici (1985) posits that when a "best" response is desirable (i.e., what he refers to as the norm of objectivity), convergence to either the majority or minority view is the most likely outcome. Several studies in social psychology have supported the application of Moscovici's theory to situations involving objective, prescriptive norms by showing that when the influence situation is based upon the norm of objectivity, views will converge to the majority and minority (Maas and Clark 1984; Nemeth and Wachter 1983). 
Moscovici's theory also suggests that the convergence of group members' views to those espoused by the majority or minority will depend upon the legitimacy of the particular views. That is, so long as the majority (minority) view is considered legitimate, convergence to the majority (minority) view will occur. Social influence research has measured legitimacy in many different ways. Some have taken a behavioral approach and considered the consistency of the view (particularly in the case of the minority dissenter) (Nemeth 1994). Others have considered it from the basis of normative power of the majority or the minority (Perez, Mugny, Butera, Kaiser and Roux 1994). We consider the legitimacy of the majority and the minority in the context of the audit profession. When considering the appropriate response to ethical dilemmas, auditors tend to rely upon laws or rules and court decisions (c.f., Massey 2002; Bernardi and Arnold 1997; Sweeney 1995; Lampe and Finn 1992; Ponemon 1990, 1992). Further, regulators and the audit profession typically recognize agreement among experts as a surrogate for accuracy when no objective criterion is available (Pincus 1990; Ashton 1985; Libby and Lewis 1982). Therefore, in the case of prescriptive discussion of ethical dilemmas, we would expect auditors in the minority to converge to the majority view after engaging in prescriptive discussion of an ethical dilemma.

Thus, consistent with conformity, we would expect the views of those auditors in the minority to change more than the views of those auditors in the majority following prescriptive discussion of an ethical dilemma. This gives rise to the first hypothesis:

Hypothesis 1: There is a greater magnitude of revision in minority members' ethical reasoning as compared to majority members' ethical reasoning following auditors' prescriptive discussion of an ethical dilemma. 


\section{Deliberative Discussion, the Norm of Pluralism, and Normalization}

Deliberative discussion involves individuals exchanging views of what realistically is done to resolve a particular situation (Scharf 1973). The effect of deliberative discussion on individuals' ethical reasoning may be found in several studies (e.g., Higgins, Power and Kohlberg 1984; Scharf 1973). For example, when attempting to set up an ethical education program for inmates, Scharf (1973) observed that inmates' deliberative discussion reflected the norms that existed in a particular context, and not what they believed was "right." Deliberative discussion appeared to reinforce the acceptance of a compromise (Higgins, Power and Kohlberg 1984), and suggests that several reasonable solutions (multiple views) may simultaneously exist. We consider deliberative discussion to be a situation where acquiescence to multiple views (i.e., the norm of pluralism) prevails (Moscovici 1985). Thus, deliberative discussion does not attempt to evoke a determination of a "best" response, but instead deliberative discussion evokes tacit acceptance that several reasonable solutions may coexist. As applied to understanding the effect of deliberative discussion on auditors' ethical reasoning, this evidence suggests that the ethical reasoning of individuals holding majority and minority views are affected by and affect deliberative discussion. This in turn suggests that deliberative discussion invites a compromise between majority and minority points of view, which is consistent with normalization.

Accordingly, the following hypothesis suggests that majority and minority views are both subject to and the source of social influence after deliberative discussion. This gives rise to the second hypothesis:

Hypothesis 2: There is no significant difference between the magnitude of the revision of majority members' ethical reasoning and minority members' ethical reasoning following auditors' deliberative discussion of an ethical dilemma. 


\section{EXPERIMENTAL APPROACH AND MEASURES}

This study uses a three-phase experiment to examine whether social influence can explain the effect of group discussion on consensus in auditors' ethical reasoning. The first phase of the experiment was the pretest to establish auditors' baseline ethical reasoning scores before they participated in group discussion of the ethical dilemmas. In the second phase of the experiment, subjects participated in either prescriptive or deliberative group discussion about the resolution of the ethical dilemmas. Prescriptive discussion is operationalized in the experiment by asking auditors to discuss what ideally should be done to resolve a realistic ethical dilemma, whereas deliberative discussion is operationalized in the experiment by asking auditors to assess what actually would be done in response to a realistic ethical dilemma. In the third phase of the experiment, subjects completed the posttest.

Many studies of social influence have determined that individuals change their latent judgments, such those encompassed in ethical reasoning, because the source of influence had some sort of normative or informational power that has the ability to sway them (e.g., Perez, Mugny, Butera, Kaiser and Roux 1994). In order to determine if the auditors changed their ethical reasoning to maintain consensus, the experiment is designed to minimize any normative or informational influences in three ways. First, given that public responses tend to make subjects more susceptible to normative influence, the auditors privately report their ethical reasoning and are instructed not to discuss the instruments that they completed in the first phase. Second, awareness that ones' views are consistent with the majority (minority) have also been shown to influence the subjects' responses (Erb, Bohner, Rank and Einwiller 2002). Some theorize that awareness of the minority and majority views evoke social identification and self-categorization (Perez, Mugny, Butera, Kaiser and Roux 1994). To minimize this potential affect, the subjects are unaware of whether they are a minority or a majority within their group. Finally, the 
subjects are randomly assigned to the groups and there is no indication that they should be or are different from their fellow group members.

The experiments require auditors to engage in group discussion of four realistic ethical dilemmas. Because empirical evidence suggests that auditors generally interact with between three-tofive other individuals when making professional judgments (Rich, Solomon and Trotman 1997; Gibbins and Mason 1988), discussion groups are composed of five auditors. The discussion groups are further classified as one of two types: high and low. High (low) discussion groups have a majority with ethical development scores above (below) the median. Since ethical development indicates how an individual considers ethical issues, it is assumed that different levels of ethical development will evoke different responses during the discussion.

Additionally, each type of discussion group (high and low) has four majority members and one minority member. Prior research (Clark 1999, 308) finds a "ceiling of influence" on group consensus decisions at three or four sources of influence; therefore, we selected a group size of five, with one minority and four majority members, to ensure that individuals were exposed to the maximum number of sources of influence. An auditor is classified as a majority (minority) group member in a high group if his or her level of ethical development is above (below) the median. Conversely, an auditor is classified as a majority (minority) group member in a low group if his or her level of ethical reasoning is below (above) the median. 


\section{Participants}

One hundred and eighty auditors provided usable data in the pretest and participated in the experimental discussion groups ${ }^{1}$. Fifty-one percent of the experimental sample is male, and on average the sample has four years of post-secondary education and a mean age of 28 years. Thirty four percent of the sample has obtained their Chartered Accountant (CA) designation. Subjects are randomly assigned to a particular experimental condition (i.e., prescriptive or deliberative). There are no significant differences across descriptive characteristics found between subjects assigned to prescriptive and deliberative conditions (see Table 1).

\section{Table 1 about here.}

Auditors included in the sample all have work experience in Canadian public accounting firms, representing a wide range of firm sizes. Thirty-eight percent $(n=68)$ of subjects in the sample are employed by a multinational firm; fifty percent $(n=90)$ are employed by a mid-size national firm, while the remaining twelve percent $(n=22)$ are employed by a small regional firm. The sample includes auditors at all hierarchical levels from staff to manager, however it does not include managers from small firms due to their unavailability.

\footnotetext{
${ }^{1}$ Note that those who did not provide complete, usable data for the pretest are omitted from the analysis. Thus, these subjects were grouped together to discuss the ethical dilemmas, but they were not required to prescriptively or deliberatively discuss the dilemmas and their responses were not analyzed.
} 


\section{Approach}

First, auditors complete the traditional three-case general DIT (Rest et al. 1999) and one version (prescriptive or deliberative) of the audit-specific four-case measure (Thorne 2000) of auditors' ethical reasoning (see Appendix 1 for a copy of the experimental instructions). The DIT measures the individuals' ethical development or the cognitive structures that they use to resolve everyday ethical dilemmas; therefore, it is considered to represent their ethical view on the world (Rest, Narvaez, Bebeau and Thoma 1999). The audit-specific four-case instrument is patterned after the DIT in format and measures the type of ethical reasoning used in evaluating professional dilemmas common to auditors. The reliability and validity of the audit-specific instrument is better or comparable to that of the Defining Issues Test (DIT) of a similar length (Thorne 2000). We instruct the auditors to not discuss the study materials until the ultimate conclusion of the study, following phase III. We then use the auditors' pretest scores on the DIT to assign auditors to a majority or minority condition in either a high or low group for the group discussion.

Approximately one-week later, auditors are given 40 minutes to either prescriptively or deliberatively discuss the audit-specific, ethical dilemmas with four of their peers who receive the same version of the audit-specific measure (prescriptive or deliberative). The auditors participate in the type of discussion that is consistent with the experimental materials in the pretest (i.e., prescriptive or deliberative). Following the group discussion, auditors are requested to again individually complete the audit-specific measure (prescriptive or deliberative). The revision to auditors' ethical reasoning scores is operationalized as the absolute value of the difference between an auditor's ethical reasoning score taken before discussion from his or her ethical reasoning score after discussion. We consider this 
revision in the auditors' ethical reasoning score to be the change in their latent judgment after the auditors take part in discussion that attempts to reduce their conflict and achieve consensus.

\section{Experimental Manipulations}

There are four experimental manipulations, the first two are directly associated with the experimental hypotheses and the last two are included in the experimental design to control for and eliminate other possible explanations for the experimental results. The first manipulation is the TYPE of discussion (i.e., prescriptive or deliberative discussion). The second manipulation is GROUP, which represents auditors' assignment to the majority or minority condition. The third manipulation is auditors' LEVEL of ethical development. The fourth manipulation is auditors' assignment to a predominately high or predominately low CONTEXT based upon whether their discussion group is composed mainly of auditors with relatively high or relatively low levels of ethical development. Each is discussed in turn.

\section{Assignment to Discussion Condition (TYPE)}

In the experiment, auditors are randomly assigned to the Prescriptive or Deliberative discussion conditions (TYPE) depending upon the version of the audit-specific measure they receive. Each version of the instrument is similar to the other except that each version elicits one particular TYPE of auditors' ethical reasoning. The prescriptive version of the audit-specific instrument requests subjects to consider how the described dilemmas ideally, should be resolved by auditors (see Appendix 1). The deliberative version of the audit-specific instrument requests subjects to consider how the described dilemmas realistically, would be resolved by auditors. 


\section{Assignment to Majority or Minority Condition (GROUP)}

In the experiment, auditors are assigned to the majority and minority conditions (GROUP) according to their level of cognitive moral development. As individuals with similar levels of cognitive moral development view ethical issues according to similar cognitive structures (c.f., Rest et al. 1999), level of ethical reasoning is used to designate subjects to the majority or the minority GROUP based upon their level of ethical reasoning relative to others in the discussion group. Auditors' ethical reasoning is measured using subject's P-score on the Thorne's (2000) four-case measure of ethical reasoning.

Thorne's (2000) instrument is modeled after Rest's (1979) Defining Issues Test. The instrument requires the subjects use to rank those issues that, in their opinion, have the most significant influence on the resolution of each dilemma. The instrument provides several responses that are the most typical modes of thinking in terms of cognitive-developmental theory (Rest, Narvaez, Bebeau and Thoma 1999). In scoring each vignette, points are assigned to each of the subject's responses using an interval scale of 1 to 4 points for the least important to the most important. Subject rankings on the four vignettes are then combined in determining subjects' P-scores - the percentage of principled considerations a subject uses in resolving the moral dilemmas - for the instrument. Thorne (2000) reports that the reliability of the $\mathrm{P}$ score on her four-case measure of ethical reasoning is comparable or better to that for the three-story DIT. She reports $(2000,149)$ test-retest reliability of $.79(.71)$ on the prescriptive (deliberative) version of her instrument. Thorne $(2000,147)$ also reports internal consistency, as measured by Cronbach's alpha, of .75 (.65) for the prescriptive (deliberative) version of her instrument. 


\section{Assignment to Higher or Lower Level of Ethical Development (LEVEL)}

To ensure that the results are not confounded by auditors' ethical development or due to the overall ethical development of the discussion groups, the experimental design crosses auditors' level of ethical development (LEVEL) with different average levels of ethical development of the discussion groups (CONTEXT). Auditors are randomly assigned to a LEVEL condition (Higher, Lower) based on their general level of ethical development, as assessed on the pre-manipulation general DIT. Auditors with levels of ethical development above the median of the sample are designated as having a Higher Level of ethical development and auditors with levels of ethical development below the median of the sample are designated as having a Lower Level of ethical development.

Auditors' level of ethical development is measured using each subject's P-score on the threecase Defining Issues Test (Rest, Narvaez, Bebeau and Thoma 1999). The reliability of the P-score on the three-case DIT ranges from about the upper sixties and seventies for the three-case DIT for both test-retest reliability and internal consistency (Rest, Narvaez, Bebeau and Thoma 1999).

\section{Assignment to High and Low Discussion Groups (CONTEXT)}

Auditors are randomly assigned to High and Low discussion groups (CONTEXT) based upon their LEVEL. High Groups are composed of four auditors at a higher level of ethical development and one auditor at a lower level of ethical development. Low Groups are composed of four auditors at a lower level of ethical development and one auditor at a higher level of ethical development. Consequently, MAJORITY members are auditors at "higher" levels of ethical development in High Groups, and auditors at "lower" levels of ethical development in Low Groups. MINORITY members are auditors at "lower" levels of ethical development in High Groups, and auditors at "higher" levels of 
ethical development in Low Groups ${ }^{2}$. Table 2 shows group composition according to DIT score and compares the level of ethical development of auditors assigned to the MAJORITY and the MAJORITY condition, across the experimental conditions.

\section{Table 2 about here.}

As per Table 2, MAJORITY members in High Groups have significantly higher levels of ethical development than MINORITY members in High Groups, and MAJORITY members in Low Groups have significantly lower levels of ethical development than MINORITY members in Low Groups $(\mathrm{p}<0.00$ in all cases $)$.

\section{Revision to Auditors' Ethical Reasoning}

The dependent variable in the analysis is the revision to auditors' ethical reasoning scores from the pretest to the posttest. The dependent variable is operationalized as the absolute value (i.e., ABSOLUTE_REVISION) of the difference between an auditor's P score on Thorne's (2000) measure of ethical reasoning taken before discussion from his or her P score on Thorne's (2000) measure of ethical reasoning taken after discussion.

\footnotetext{
${ }^{2}$ Statistical techniques are used to ensure that the results are attributable to differences in the MAJORITY and the MINORITY and not to differences in DIT scores of auditors and audit groups.
} 


\section{RESULTS}

\section{Results for Hypothesis 1}

Hypothesis 1 posits that prescriptive discussion results in a significantly greater revision to the ethical reasoning scores of minority group members than majority group members. We use a 2 × 2 × 9 (LEVEL x CONTEXT x GROUP nested within CONTEXT) ANOVA to test hypothesis 1 and examine the effects of discussion on the revision to the ethical reasoning scores of auditors in the prescriptive condition. We use the variable, GROUP nested within CONTEXT, rather than GROUP to assess hypothesis 1 because GROUP (majority or minority group membership) is inextricably linked to CONTEXT (whether the subject is in a high or low group). That is, majority or minority GROUP membership is inseparable from CONEXT.

\section{Table 3 about here.}

For subjects in the prescriptive condition, Table 3 reports significance for the variable, GROUP nested within CONTEXT $(\mathrm{p}<0.02)$, which suggests that the revisions to prescriptive reasoning of auditors in the majority and minority conditions (GROUP) are statistically different according to high and low groups (CONTEXT). This finding suggests there may be support for Hypothesis 1. However, further investigation testing the directional implications of this finding is required.

Table 4 shows that for auditors in the minority, the absolute revision to prescriptive reasoning scores was significantly greater (at $\mathrm{p}=0.03$ ) than the absolute revision to prescriptive reasoning scores of auditors in the majority. Thus, the results support Hypothesis 1. 
Table 4 about here.

\section{Results for Hypothesis 2}

To test whether deliberative discussion results in the normalization of auditors' ethical reasoning, Hypothesis 2 postulates that there is no significant difference in the magnitude of the revision to the ethical reasoning between group members in the majority as compared to those in the minority. To look at the differential effect of deliberative discussion on group members more closely, Table 5 compares the absolute revision to the ethical reasoning scores of majority and minority GROUP auditors who engage in deliberative discussion.

The results of Table 5 show no significant difference between the absolute revision to the deliberative ethical reasoning of auditors assigned to the majority condition and auditors assigned to the minority condition $(\mathrm{p}<0.13)^{3}$. This result contrasts with that found for prescriptive discussion where, consistent with the conformity hypothesis, there is a significantly greater revision in the ethical reasoning of those in the minority than in the majority ${ }^{4}$.

\section{Table 5 about here.}

\footnotetext{
${ }^{3}$ In addition, previous research shows that there is a significant revision only to the ethical reasoning scores of auditors engaged in discussion (both prescriptive and deliberative discussion) while there is no significant revision to the ethical reasoning scores of auditors in an individual control condition who do not engage in discussion (Thorne and Hartwick 2001).

${ }^{4}$ To ensure that the results of this comparison are not attributable to level or context, a 2 (LEVEL) by 2 (CONTEXT) by 9 (GROUP nested within CONTEXT) ANOVA examines the effects of discussion on the ethical reasoning scores of auditors assigned to the deliberative condition. The results of this ANOVA suggests that deliberative discussion does not result in a significant difference in the magnitude of the revision to MINORITY or MAJORITY auditors' ethical reasoning.
} 


\section{DISCUSSION AND LIMITATIONS}

This study introduces Moscovici’s $(1976,1985)$ model of social influence to the accounting research domain, and integrates Moscovici's theory with the cognitive-developmental perspective on ethical reasoning. This paper uses Moscovici's theory as a basis for understanding how group discussion may affect consensus in auditors' ethical reasoning. By so doing, this research provides insight into factors that may affect the achievement of consensus in auditors' professional judgment of an ethical nature. The results of this study show that the influence of discussion of ethical dilemmas differentially affects auditors' minority and majority views, and this influence varies according to type of discussion that takes place. Prescriptive discussion appears to cause convergence in the minority's reasoning to the majority view (i.e., conformity), whereas deliberative discussion appears to cause normalization in auditors' ethical reasoning.

Moscovici’s (1985) theory appears to be particularly appropriate for understanding the effect of discussion on ethical reasoning because the interpretative nature of ethical dilemmas may give those in the minority, as well as the majority, the scope and the latitude for influence. The audit literature's historical reliance on the classical social-psychological perspective may have contributed to the widespread acceptance of substantive agreement as desirable in auditors' professional judgement. The results of this study suggest that for professional judgments with an inherent ethical component, lack of substantive agreement may not be a reflection of auditors' incompetence or inaccuracy but may merely be a reflection of the characteristics of the type of decision itself. This in turn suggests that lack of agreement among auditors is not necessarily bad or negative, but may be acceptable when considering professional judgments of an ethical nature. Furthermore, it may be inferred from the findings of Thorne and Hartwick (2001) that the cost of consensus for auditors considering pragmatic resolutions to 
professional ethical judgments may unfortunately be a deterioration in ethical reasoning as auditors tend to compromise when striving for the "actual" (versus "ideal") resolution to a particular ethical dilemma. Indeed, in the case of the Enron meeting, perhaps if the partners attempted to discuss what they ideally should do, and focus on the professional principals of integrity, due care, and objectivity, it is possible that the conclusion the partners reached would have been different.

Further work, with particular consideration to the legitimacy of multiple viewpoints inherent in particular auditing contexts and judgments, is needed to provide additional insights into understanding factors that affect majority and minority views. The explicit or implicit encouragement of acceptance of a single "right" response through the use of practices and procedures adopted by auditors (e.g., standardized audit protocols, decision-aids and consultation groups) may sometimes be misguided as implied in the multiple audit failures that have recently occurred. Additional care is needed to determine the type of social influence that will affect auditors' ethical decision process and whether majority and/or minority influence should be encouraged and/or discouraged in the formulation of auditors' professional judgement. Of particular relevance is the stream of research that demonstrates that a consistent and committed minority has the ability to change the views of the majority and to encourage innovative and creative decisions (Nemeth, Brown, and Rogers 2001; Nemeth 1994). Perhaps Arthur Andersen would not have accepted Enron's aggressive reporting if processes were in place that encouraged a "devil's advocate" role. Future research should consider what conditions encourage the majority and the minority views to dominate and/or recede, and what contexts encourage or discourage similarity in auditors' judgments.

We also see potential for future research in considering the role of courage in social influence. Some preliminary research indicates that courage and a sense of conviction improves the 
quality of group decisions (Nemeth and Chiles 1998). Since courage is a necessary virtue of an auditor (Libby and Thorne 2003), it may help explain how auditors resist social influence or are able to influence the outcome of group discussions.

A few caveats are in order in interpreting the conclusions of the study. The first caveat is with regard to the size and nature of the sample. A significant effort was made to obtain a sufficient number of subjects with a wide range of auditing experience. Replication of this study with an even greater number of subjects will increase our assurance that its results are representative. Furthermore, this study should also be replicated using groups of different sizes and different compositions of majority and minority members. In addition, the applicability of the results of this study to auditors not included in the sample (e.g., audit partners and sole practitioners) and to organizations that are not audit firms remains to be established.

The second caveat is with regard to the nature of the setting in which the study was carried out. The nature of the experiment required the interaction of a large number of auditors; consequently, it was conducted during audit firms' training courses or during class time of courses attended by accountants for professional accreditation. However, using locations and contexts that are not representative of the location or context in which these discussions usually are made may have hindered the elicitation of realistic discussion. For instance, by design, the discussion groups included auditors at similar hierarchical ranks; therefore, the results of the experiment may not apply to situations where different hierarchical levels are involved in-group discussion. Since hierarchy and accountability can influence the outcome of audit group and individual decisions this is an important area for future research (Rich, Solomon and Trotman 1997), we envision that a hierarchical setting would evoke normative pressures not present in our current study. 
The third caveat is with regard to the types of discussion elicited in the experimental manipulations. The experimental instructions and procedures attempted to ensure that a single type of discussion was encouraged in each experiment. Manipulation checks and researcher observation confirmed that groups engaged in discussion in the assigned mode (i.e., prescriptive or deliberative). Thus, this study did not examine the effect of social interaction on auditors' resolution of ethical dilemmas when discussion involved both types of ethical reasoning, either simultaneously or sequentially. Additional work is required to ascertain the effect of social influence on auditors' resolution of ethical dilemmas when both types of discussion are involved.

Finally, the study examined auditors' ethical reasoning immediately after the group discussion. The experiment was not designed to determine whether the effect of discussion is persistent over time. Future investigations to ascertain the longevity of the effect of a single discussion on auditors' ethical reasoning and to ascertain the influence of repeated conversations on auditors' ethical reasoning are likely to be of interest to those concerned with understanding how social influence affects auditors' ethical reasoning. 


\section{BIBLIOGRAPHY}

Abdel-khalik, A., Snowball, D. and D. Wragge. 1983. The effects of certain internal audit variables on the planning of external audit programs, The Accounting Review, pp. 215-227.

Arnold, D., Bernardi, R. and P. Neidermeyer. 1999. The effect of independence on decisions concerning additional audit work: A European perspective. Auditing: A Journal of Practice and Theory, 18:45-67.

Arnold, V., Sutton, S., Hayne, S., and C. Smith. 2000. Group decision-making: The impact of opportunity cost, time pressure and group support systems, Behavioral Research in Accounting, p. 69-96.

Asch, S. 1951. Effects of group pressure upon the modification and distortion of judgements, Groups, Leadership and Men, Guetzkow, H. (Ed.), (Pittsburgh: Carnegie Press) pp.177-190.

Asch, S. 1955. Opinions and social pressure, Scientific American, 193: pp. 31-35.

Asch, S. 1956. Studies of independence and conformity: a minority of one against a unanimous majority. Psychological Monographs. 70(9).

Ashton, A. 1985. Does consensus imply accuracy in accounting studies of decision-making?, Accounting Review, 67: pp.173-185.

Bamber, E., Watson, R. and M. Hill. 1996. The effects of group support system technology on audit group decision-making. Auditing: A Journal of Practice and Theory, Spring: (1996) pp.122134.

Barnlund, D. 1959. A comparative study of individual, majority and group judgment, Journal of Abnormal Social Psychology, January, pp.55-60.

Bernardi, R. and D. Arnold. 1997. An examination of moral development within public accounting by gender, staff level and firm, Contemporary Accounting Research, Vol. 14: 653-668.

Clark III, R. 1999. Effect of number of majority defectors on minority influence. Group Dynamics: Thoery, Research and Practice, 3 (4), pp. 303-312.

Davison, M. and S. Robbins. 1989. The Reliability And Validity Of Objective Indices Of Moral Development. Applied Psychological Measurement 2, (3), 391-403.

Einhorn, J. 1974. Expert judgment: Some necessary conditions and an example. Journal of Applied Psychology, 59, 562-571. 
Erb, H., G. Bohner, S. Rank, and S. Einwiller. 2002. Processing minority and majority communications: The role of conflict with prior attitudes. Personality and Social Psychology Bulletin, Vol 28: 1172-1182.

Francis, J. 1990. After virtue? Accounting as a moral and discursive practice, Accounting, Auditing and Accountability Journal, pp.5-17.

Gaa, J. 1993. The Ethical Foundations of Public Accounting, CGA-Canada Research Foundation.

Gibbins, M. and A. Mason. 1988. Professional Judgment in Financial Reporting, CICA Research Study, Toronto.

Higgins, A., Power, C. and L. Kohlberg. 1984. The relationship of moral atmosphere to judgments of responsibility. In: W. M. Kurtines \& J. L. Gerwirth, eds. Morailty, Moral Behavior and Moral Development. New York: Wiley, pp. 74-106.

Jones, T. 1991. Ethical decision making by individual in organizations: An issue-contingent model. Academy of Management Review, 16 (2): 366-395.

Keasey, K. and R. Watson. 1989. Consensus and accuracy in accounting studies of decision-making: A note on a new measure of consensus. Accounting, Organizations and Society, 14(4): $337-$ 345

Kohlberg, L. 1958. The Development of Modes of Ethical Thinking and Choice in the Years Ten to Sixteen, Doctoral Dissertation, University of Chicago.

Lampe, J., and D. Finn. 1992. A model of auditors' moral processes. Auditing: A Journal of Practice and Theory, 11, Supplement, pp.33-59.

Levine, J., and E. Russo. 1987. Majority and minority influence. In C. Hendrick, ed., Review of Personality and Social Psychology: Group Processes, 8, pp. 13-54. Newbury park, CA: Sage.

Libby, R. and Lewis, B. 1982. Human information process research in accounting: The state of the art in 1982, Accounting, Organisations and Society, 7, 3, pp.231-285.

Libby, T. and L. Thorne. 2003. The identification and categorization of auditors' virtue, Business Ethics Quarterly, forthcoming.

Lord, A. and F. DeZoort. 2001. The impact of commitment and moral reasoning on auditors' responses to social influence pressure, Accounting, Organisations and Society, 26, 3, pp.215236. 
Louwers, T. , Ponemon, L. and R. Radtke. 1997. Examining Accountants' Ethical Behaviour: A Review and Implications for Future Research, in Behavioral Accounting Research; foundations and Frontiers, (Ed.) V. Arnold and S. Sutton, American Accounting Association.

Maas, A. and R. Clark. 1984. Hidden impacts of minorities: Fifteen years of minority influence research. Psychological Bulletin, 95, pp. 428-540.

Massey, D. 2002. The importance of context in investigating auditors' moral abilities. Research on Accounting Ethics, 8, pp. 195-247.

Moscovici, S. 1976. Social Influence and Change. London: Academic Press.

Moscovici, S. 1980. Toward a theory of conversion behaviour. Advances in experimental social psychology, (Ed.) L. Berkowitz, 13, (New York, Academic Press).

Moscovici, S. 1985. Social influence and conformity, The handbook of social psychology, 3rd edition, (Ed.) G. Lindsey and E. Aronson, (New York, Random House), pp.347-412.

Moscovici, S. and C. Faucheux. 1982. Social influence, conformity bias, and the study of active minorities. Advances in experimental social psychology, vol. 6. (Ed.) L. Berkowitz, (New York: Academic Press).

Nemeth, C. 1985. Compromising public influence for private change. Perspectives on Minority Influence, (Ed) S. Moscovici, G. Mugney, and E. Van Avermaet. (Cambridge: Cambridge University Press), pp. 75-89.

Nemeth, C. 1994. The value of minority dissent. Minority Influence, (Ed.) S. Moscovici, A. MucchiFaina, and A. Maas. (Chicago: Nelson-Hall), pp. 3-16.

Nemeth, C., Rogers, J. and K. Brown. 2001. "Devil's advocate vs. authentic dissent: Stimulating quantity and quality.” European Journal of Social Psychology, 31, pp. 707-720.

Nemeth, C. and C. Chiles. 1998. Modeling courage: The role of dissent in fostering independence. European Journal of Social Psychology 18, pp. 275-280.

Nemeth, C. and J. Wachter. 1983. Creative problem solving as a result of majority vs. minority influence. European Journal of Social Psychology 7, pp. 45-55.

Perez, J., Mugny, G., Butera, F., Kaiser, C. and P. Roux. 1994. Integrating minority and majority influence: Conversion, consensus, and uniformity. Minority Influence, (Ed.) S. Moscovici, A. Mucchi-Faina, and A. Maas. (Chicago: Nelson-Hall), pp. 185-208. 
Pincus, K. 1990. Audit Judgement Consensus: A Model for Dichotomous Decisions, Auditing: A Journal of Practice and Theory, Spring, 9, No. 2.

Ponemon, L. 1990. Ethical judgments in accounting: A cognitive-developmental perspective. Critical Perspectives in Accounting 1: 191-215.

Ponemon, L. 1992. Accountant underreporting and moral reasoning: An experimental lab study. Contemporary Accounting Research, 9, 1, Fall, pp. 171-189.

Ponemon, L. 1993. The influence of ethical reasoning on auditors' perception of management's integrity and competence. Advances in Accouting. 1-23.

Ponemon, L. and D. Gabhart. 1993. Ethical Reasoning in Accounting and Auditing, Vancouver, Canada: Canadian General Accountants’ Research Foundation.

Reckers, P. and J. Schultz. 1982. Individual versus group assisted audit evaluations, Auditing: A Journal of Practice and Theory, Fall, pp.64-74.

Rest, J. 1979. Development in Judging Moral Issues. Minneapolis, MN: University of Minnesota Press.

Rest, J., Narvaez, D., Bebeau, M. and S. Thoma. 1999. Post-conventional Moral Thinking: A NeoKohlbergian Approach. Center for the Study of Ethical Development, Minneapolis, MN: University of Minnesota Press.

Rich, J., Solomon, I. and K. Trotman. 1997. Multi-auditor judgment/decision making research: A decade later. Journal of Accounting Literature. 16: 86-126.

Scharf, R. 1973. Moral Atmosphere and intervention in the prison, PhD dissertation, Harvard University.

Schultz, J. and P. Reckers. 1981. The impact of group processing on selected audit disclosure decisions, Journal of Accounting Research, Autumn, pp.482-501.

Sherif, M. 1935. A study of some human factors in perception. Archives of Psychology. 22, No. 187, pp. 1-60.

Solomon, I. 1982. Probability assessment by individual auditors and audit teams: An empirical investigation, Journal of Accounting Research, 20, (1982), pp. 689-710.

Solomon, I. 1987. Multi-auditor judgment/decision making research, Journal of Accounting Literature, 6, pp.1-25. 
Sweeney, J. 1995. The ethical expertise of accountants: An exploratory analysis. Research in Accounting Ethics 1, pp. 213-234.

Thorne, L., 2000. The Development of two measures to assess accountants' prescriptive and deliberative moral reasoning, Behavioral Research in Accounting, pp.139-170.

Thorne, L., and Hartwick, J., 2001, The directional effects of discussion on auditors' moral reasoning, Contemporary Accounting Research, 18 (Summer), pp. 337-361..

Wright, W. 1988. Audit judgment consensus and experience. In Behavioral Accounting Research: A Critical Analysis, K. R. Ferris, ed., New York: Publishing Horizons. 
Appendix 1: Prescriptive Instrument and Experiment Instructions (Phases II and III)

INSTRUCTIONS TO PARTICIPANTS

\section{CONTENTS AND DISTRIBUTION OF MATERIALS}

In addition to a copy of these instructions to be distributed to each member of the group, this envelope should contain:

1) five envelopes with identification codes of each of the group members on the outside;

2) five two-page case descriptions (one for each member), and

3) one one-page response sheet (one for the entire group).

Please distribute to each member of the group one two-page case description and his or her envelope with his or her identification code written on the outside. These envelopes are not be to opened until the group discussion has been completed.

\section{GROUP DISCUSSION}

During this session you will be asked to discuss four accounting cases that were included in the preparatory material. Your group should allocate about 10 minutes per case to the discussion of each case. Consider that your group is a professional disciplinary committee whose role is to determine and describe the ideal response to this ethical dilemma. The focus of the discussion should be on which factors are important to the resolution of the professional dilemma described in each case as required by the attached form. After discussing each case, please complete the attached response sheet that has room for you to describe: 1) how the dilemma ideally should be resolved by a professional accountant, and 2) the four factors which are most important to its resolution. Be sure to give each and every member of your group a chance to express his/her opinion. You may start now.

After completing the discussion of all four cases, please return the attached form and the two-page case descriptions to the original envelope and seal it shut.

\section{INDIVIDUAL ENVELOPES}

On an individual basis, each group member is to open the envelope with his or her identification code and follow the instructions included inside.

If at any time you need clarification of these instructions, please do not hesitate to ask. Thank you for your cooperation. 
Identification code

We are now asking for you to redo the questionnaire, which examines your own individual analysis of the four accounting cases, you just reviewed. We ask you to record your response, as you perceive the accountant described in the case ideally should respond to the ethical dilemma. It may help to think of your response as advice you, a member of a professional disciplinary committee, give to the accountant described in the case. He/she has requested your guidance on what is the most ethical solution to his/her dilemma and which factors are most critical for resolving the dilemma while maintaining the highest standard of ethical conduct.

The instructions for filling out this questionnaire have not changed from when you filled it out previously. They are included for a reference.

The cases have been carefully written to encourage you to consider what factors are important to the particular decision choice. Be sure that every form is complete. Please do not go back and change responses to cases that have already been completed.

Once you finish one case, please proceed immediately to the next. When all four cases have been completed, place the completed questionnaire into its original envelope. Your assistance and cooperation are greatly appreciated. 
Here is an illustration case and sample questionnaire.

Simon Fellows is thinking about buying a house. He is married, in his early thirties, has two small children, and earns an average income. No additions to his family are planned. His family has two cars and his wife works. Simon comes to you for advice as to whether he should or should not buy a house.

Should Simon buy a house? (Check one) _ X Yes _ Can't decide_ _No

In the process of advising Simon whether or not he should buy the house, you may consider many different issues to be important. Below is a list of some of these issues. On the left-hand side of each statement check the space, which best corresponds to the importance you believe should be given to the particular consideration. (For instance, if you think that statement \#1 should be of great importance in making a decision about buying a house, check the space on the left).

IMPORTANCE:

\begin{tabular}{|l|l|l|l|l|}
\hline Great & uch & Some & Little & No \\
\hline $\mathrm{X}$ & & & & \\
& & & & \\
\hline & & & & $\mathrm{X}$ \\
\hline & $\mathrm{X}$ & & & \\
\hline $\mathrm{X}$ & & & & \\
\hline
\end{tabular}

1. Whether Simon can afford a suitable house. (Note in this example, the person taking the questionnaire thought that Simon should place great weight on this consideration in reaching his decision).

2. Whether the furnace on the house was thermal dynamic (Note that if a statement sounds like gibberish, nonsense or is not relevant to the question at hand; mark it of "no importance").

3. Whether Simon could still go on his annual golf vacation.

4. Whether Simon's wife wants to buy a house.

From the list above, rank the four items of the greatest importance to an "ideal" response:

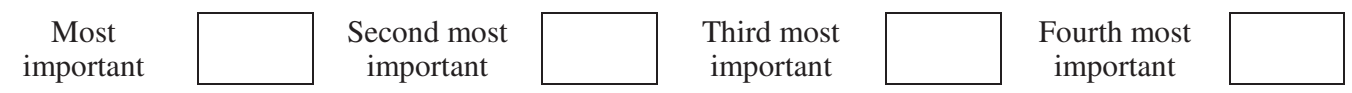

Included in the questionnaire are some words and sentences that are not clear or do not make sense. Please mark these "no" of no importance and do not include them in your ranking.

Note in this example, the top choices come from those statements that were checked on the left-hand side statements \#1 and \#4 were thought to be very important. In deciding what is the most important, a person would reread \#1 and \#4, then pick one of them as the "most important" and put the other one as "second most important". Statement \#3 would be ranked as the net highest importance; therefore, \#3 would be put beside the "third most important" choice. Finally, statement \#2 was of the fourth highest importance; therefore, \#2 would be put beside the "forth most important" choice.

Please do not go back and change responses to cases that you have already completed. Once you finish one case, please proceed immediately to the next. Your assistance and cooperation are greatly appreciated. 


\section{ETHICAL DILEMMAS OF ACCOUNTANTS}

We ask you to respond to the following four cases as you perceive the accountant, ideally, ought to in the described situation. It might help to think of you as a member of a professional disciplinary committee whose role is to advise on the ideal way in which the situation described in the case should be resolved. Your mandate is to identify the four most important factors, which, ideally, should be critical of the ethical resolution of the described dilemma. 
ALICE AND THE ABC COMPANY

Alice is a senior auditor and a CPA for a national CPA firm that provides auditing, tax and consulting services. The firm has developed a package called the ACME ACCOUNTING SYSTEM, which is sold to the general public as well as to the firm's clients. Alice is the auditor in charge of the fieldwork on the ABC Company, Inc. audit. During the course of this audit assignment, Alice is asked to evaluate the quality control of the accounting system, which happens to be the ACME package. Alice uncovers several severe control weaknesses in the ACME system. Before rendering the management letter to ABC management, Alice is told by her boss to modify the negative comments regarding the ACME package.

Ideally, should Alice amend the management letter? (Check one)

Should amend it ___ Can't decide___ Should not amend it

In the process of advising Alice whether or not she should amend the management letter, many items need to be considered. Below is a list of some of these issues. Please indicate the importance of each of the following considerations:

Importance:

\begin{tabular}{|c|c|c|c|c|}
\hline Great & uch & Some & Little & No \\
\hline & & & & \\
\hline & & & & \\
\hline & & & & \\
\hline & & & & \\
\hline & & & & \\
\hline & & & & \\
\hline & & & & \\
\hline & & & & \\
\hline & & & & \\
\hline & & & & \\
\hline & & & & \\
\hline & & & & \\
\hline
\end{tabular}

1. Whether the weaknesses in the ACME system may be easily remedied by compensating controls.

2 . Wouldn't a good employee defer to her superior's judgment?

3. Whether Alice's job may be threatened by her refusal to revise the letter.

4. Whether fair deliberation on the client's financial position can predict professional reputation.

5. What is best for Alice's firm?

6. Whether or not Alice has a duty to ensure that the management letter is accurate.

7. What is the potential value of an independent audit in lieu of society's current perspective on an enterprise's net worth?

8 . How is society best served?

9. Whether any clients really care about internal control issues or if all they ever really want is a clean audit opinion.

10. Would amending the management letter be consistent with what Alice thinks is right?

11. What action would Alice's peers in the audit firm expect her to take?

12. What factors are relevant in determining Alice's professional responsibility?

From the list above, rank the four items of the greatest importance to an "ideal" response:

Most

important 2nd most

important 3rd most

important 4th most

important 
BILL AND DOGWOOD CONSTRUCTION

Bill is a staff auditor and CPA for a small firm that provides auditing services. The President of the Dogwood Construction Corporation is searching for a Chief Financial Officer, and has asked Bill to help recruit and select an appropriate candidate. Bill is the "in-charge" auditor on the Dogwood engagement, which is among the largest and most profitable jobs for the firm. Bill truly believes that he can provide a valuable service to Dogwood as well as his firm by performing the function. In addition, Bill already knows an individual, a personal friend, who has the right qualifications for this very important position.

Ideally, should Bill assist Dogwood's president? (Check one)

\section{Should assist him Can't decide Should not assist him}

In the process of advising Bill whether or not he should assist Dogwood's president, many different issues need to be considered. Below is a list of some of these issues. Please indicate the importance of each of the following considerations:

Importance:

\begin{tabular}{|l|l|l|l|l|}
\hline Great & uch & Some & Little & No \\
\hline & & & & \\
\hline & & & & \\
\hline & & & & \\
\hline & & & & \\
\hline & & & & \\
\hline & & & & \\
\hline & & & & \\
\hline & & & & \\
\hline & & & & \\
\hline
\end{tabular}

1. What effect will Bill's refusal have on his firm's relationship with the client?

2. Whether Bill has the right to assist a client in the selection and recruitment of a Chief Financial Officer.

3. Whether employment referrals ought to be in the hands on a few greedy headhunters.

4. Does telling his friend the job is available constitute an infringement of Bill's professional responsibilities?

5. Will having a friend as the controller prevent Bill from making a fair assessment of the firm's financial position in the future?

6. Whether Bill is overweight or has a weakness for fast food.

7. Whether the audit partner of the Dogwood audit will endorse Bill's actions.

8. Wouldn't a good auditor refuse to assist Dogwood's president?

9. What actions would Bill's friend expect him to take?

10. Would it be fair to other clients of the firm if Bill assisted Dogwood's president?

11. Would assisting the president in any way violate the rights of others?

12. Would refusing to assist the president be consistent with what Bill thinks is right?

From the list above, rank the four items of the greatest importance to an "ideal" response:

Most

important

\section{2nd most}

important 3rd most

important 4th most

important 


\section{JOHN AND THE FOLDERS' AUDIT}

John is a CPA and the senior in charge of the fieldwork for two legally unrelated audit clients: the Folders Company and Colby Corporation. While on the Folders job, John learns that Colby is the only supplier of a product that is critical to the manufacturing of Folders' final output. Colby is the only vendor in the marketplace. The next day, John learns from Colby's management that they are greatly increasing the price of their primary products--and the new pricing policy can bankrupt Folders. John knows that Folders recently considered the acquisition of a small company in Asia that with some effort can redirect its production to produce a product similar to the one made by Colby. However, the estimated unit cost was greater than the present (known and assumed stable) prices offered by Colby. Based on their limited information, Folders did not seriously consider the purchase of this small company.

Ideally, should John disclose Colby's plans to Folders? (Check one)

\section{Yes}

Can't decide

No

In the process of advising John whether or not he should disclose Colby's plans to Folders, many different items need to be considered. Below is a list of some of these issues. Please indicate the importance of each of the following items to John's response:

Importance:

\begin{tabular}{|l|l|l|l|l|}
\hline Great & uch & Some & Little & No \\
\hline & & & & \\
\hline & & & & \\
\hline & & & & \\
\hline & & & & \\
\hline & & & & \\
\hline & & & & \\
\hline & & & & \\
\hline & & & & \\
\hline & & & & \\
\hline
\end{tabular}

1. Is John obliged to maintain client confidentiality regardless of circumstance?

2. Whether the partner on the audit will endorse John's actions.

3. What is best for the reputation of John's firm?

4. Whether Folders' reliance on a single supplier is disclosed in the financial statements.

5. Whether client confidentiality is the ultimate prelude to the necessity of rendering an audit opinion.

6. Which course of action will bring about the greatest good for all society?

7. How will others perceive John's actions in the audit firm?

8. Whether the Folders Company brought this upon itself by relying solely upon one supplier.

9. Whether John's actions will go against regulatory standards with respect to insider information.

10. What values are the bases for determining which stakeholder's interest takes precedence when they conflict?

11. Would John's action be consistent with what he believes is just?

12. Whether the reputation of the audit profession will suffer if Folders goes bankrupt.

From the list above, rank the four items of the greatest importance to an "ideal" response:

Most

important

\section{2nd most}

important

\section{3rd most}

important 4th most

important 
BOB AND CORA LIMITED

Bob is a brand new partner in a medium-size audit firm. Bob has inherited a large amount of business as a result of the unanticipated demise of one of the firm's founders. In fact, Bob has had the good fortune to be granted the audit of the firm's largest and oldest client, Cora Limited, and its 70 percent-owned subsidiary, Corinne Incorporated. Bob discovers that Cora Limited has historically been charging an exorbitant management fee to Corinne Incorporated. Bob is concerned that the interests of the minority shareholders of Corinne Incorporated are materially compromised by such an arrangement. In discussions with the client, Bob learns that this procedure was undertaken several years ago upon the advice of his own firm's tax department. This procedure is used to boost Cora's earnings to take advantage of significant tax savings that would otherwise be lost to Cora Limited. Cora's management is not amenable to losing these tax savings. The magnitude of all related party transactions between Cora Limited and Corinne Incorporated is disclosed in the financial statements as required by accounting standards. Consequently, submits Cora's management, the financial statements of Cora Limited and Corinne Incorporated are fairly presented.

Ideally, should Bob insist on separate disclosure of the management fee by Cora Limited?

Yes_Can't decide __ No

In the process of advising Bob on whether or not he should insist that Cora disclose the management fee, many different issues need to be considered. Below is a list of some of these issues. Please indicate the importance of each of the following considerations:

Importance:

\begin{tabular}{|l|l|l|l|l|}
\hline Great & uch & Some & Little & No \\
\hline & & & & \\
\hline & & & & \\
\hline & & & & \\
\hline & & & & \\
\hline & & & & \\
\hline & & & & \\
\hline & & & & \\
\hline & & & & \\
\hline
\end{tabular}

1. Whether other partners in the firm will support Bob's position.

2. Would it be fair to the tax department if Bob did not insist that the management fee be disclosed?

3. Whether anybody really cares about GAAP in his or her efforts to exploit everyone else.

4. Whether a retroactive adjustment to the financial statements is required.

5. Whether or not disclosure of the management fee would benefit more people to a greater extent.

6. What is the quintessence of an audit apart from displacement, especially for minority shareholders?

7. Is Bob obliged by professional standards to assess the reasonableness of the management fee?

8. Whether it is generally accepted that firms manipulate the amount of management fees between associated companies to minimize their tax liability.

9. What is the financial importance of the Cora audit to Bob's firm?

10. Doesn't Bob have a professional duty to protect the rights of minority shareholders?

11. Would Bob's decision be consistent with his own personal beliefs?

12. What values are the bases for governing fair presentation when conventional reporting practices do not result in full disclosure?

From the list above, rank the four items of the greatest importance to an "ideal" response:

Most

important 2nd most

important

\section{3rd most}

important 4th most

important 
Table 1: Mean Descriptive Characteristics of Subjects in Total and by Experimental Condition

\begin{tabular}{|c|c|c|c||}
\hline & Prescriptive & Deliberative & Total \\
\hline $\begin{array}{c}\text { Gender (percent male) } \\
\text { (Standard deviation) }\end{array}$ & $\begin{array}{c}.49 \\
.5)\end{array}$ & $\begin{array}{c}.53 \\
(.5)\end{array}$ & $\begin{array}{c}.51 \\
.5)\end{array}$ \\
\hline $\begin{array}{c}\text { Average Age } \\
\text { (Standard deviation) }\end{array}$ & $\begin{array}{c}28 \text { years } \\
(5.5)\end{array}$ & $\begin{array}{c}28 \text { years } \\
(5.3)\end{array}$ & $\begin{array}{c}28 \text { years } \\
(5.4)\end{array}$ \\
\hline $\begin{array}{c}\text { Average work experience in an } \\
\text { audit firm }\end{array}$ & 3.4 years & 3.3 years & 3.4 years \\
(Standard deviation) & $(3)$ & $(3)$ & $(3)$ \\
\hline $\begin{array}{c}\text { CA designation (percent) } \\
\text { (Standard deviation) }\end{array}$ & $\begin{array}{c}.22 \\
(.4)\end{array}$ & $\begin{array}{c}.28 \\
. .5)\end{array}$ & $\begin{array}{c}.25 \\
(.4)\end{array}$ \\
\hline $\begin{array}{c}\text { DIT score } \\
\text { (Standard deviation) }\end{array}$ & $\begin{array}{c}37.3 \\
(17.0)\end{array}$ & $\begin{array}{c}39.9 \\
(17.0)\end{array}$ & $\begin{array}{c}38.6 \\
(16.9)\end{array}$ \\
\hline $\begin{array}{c}\text { Years of post-secondary education } \\
\text { completed }\end{array}$ & 4 & 4 & 4 \\
(Standard deviation) & $(.9)$ & $(.9)$ & $(.8)$ \\
\hline Total sample size & 90 & 90 & 180 \\
\hline * there are no significant differences in attributes between experimental groups
\end{tabular}




\begin{tabular}{|c|c|c|}
\hline \multicolumn{3}{|c|}{ Table 2: DIT scores by Experimental Condition } \\
\hline \multicolumn{3}{|c|}{ Prescriptive Condition } \\
\hline & $\begin{array}{c}\text { Predominantly High } \\
\text { Discussion Groups }\end{array}$ & $\begin{array}{l}\text { Predominantly Low } \\
\text { Discussion Groups }\end{array}$ \\
\hline $\begin{array}{c}\text { Majority members-DIT } \\
\text { score } \\
\text { (standard deviation) } \\
n\end{array}$ & $\begin{array}{c}53.1 \\
(10.4) \\
36\end{array}$ & $\begin{array}{c}26.2 \\
(9.2) \\
36\end{array}$ \\
\hline $\begin{array}{c}\text { Minority members-DIT } \\
\text { score } \\
\text { (standard deviation) } \\
n\end{array}$ & $\begin{array}{c}26.2 \\
(9.2) \\
9\end{array}$ & $\begin{array}{c}55.6 \\
(12.5) \\
9\end{array}$ \\
\hline $\begin{array}{c}\text { t-value for equality of } \\
\text { means } \\
\text { Significance }\end{array}$ & $\begin{array}{c}7.01 \\
\mathbf{p}<0.00\end{array}$ & $\begin{array}{c}7.92 \\
\mathbf{p}<0.00\end{array}$ \\
\hline \multicolumn{3}{|c|}{ Deliberative Condition } \\
\hline $\begin{array}{c}\text { Majority members-DIT } \\
\text { score } \\
\text { (standard deviation) } \\
n\end{array}$ & $\begin{array}{c}50.3 \\
(10.2) \\
36\end{array}$ & $\begin{array}{c}23.9 \\
(10.0) \\
36\end{array}$ \\
\hline $\begin{array}{c}\text { Minority members-DIT } \\
\text { score } \\
\text { (standard deviation) } \\
n\end{array}$ & $\begin{array}{c}22.2 \\
(9.2) \\
9\end{array}$ & $\begin{array}{c}53.7 \\
(10.9) \\
9\end{array}$ \\
\hline $\begin{array}{c}\text { t-value for equality of } \\
\text { means } \\
\text { Significance }\end{array}$ & $\begin{array}{c}7.47 \\
\mathbf{p}<0.00\end{array}$ & $\begin{array}{c}7.80 \\
\mathbf{p}<0.00\end{array}$ \\
\hline
\end{tabular}


Table 3: ANOVA of the ABSOLUTE_REVISION to ethical reasoning scores assigned to the prescriptive condition.

\begin{tabular}{|l|l|r|r|r|r|}
\hline$\underline{E F F E C T}$ & Source of Variation & DF & MS & F & p-value \\
\hline FACTORS & WITHIN + RESIDUAL & 54 & 59 & & \\
& LEVEL & 1 & 35 & 0.60 & 0.22 \\
& CONTEXT & 1 & 60 & 1.03 & 0.16 \\
& LEVEL*CONTEXT & 1 & 271 & 4.62 & 0.02 \\
& LEVEL*GROUP & 16 & 121 & 2.07 & 0.01 \\
& within CONTEXT & & & & \\
& GROUP within & 16 & 113 & 1.93 & 0.02 \\
& CONTEXT & & & & \\
\hline
\end{tabular}


Table 4: Absolute Revision to Prescriptive Ethical Reasoning Scores by Group

\begin{tabular}{|l|l|}
\hline $\begin{array}{l}\text { Majority members-absolute revision } \\
\text { (standard deviation) }\end{array}$ & $\begin{array}{l}9.6 \\
(7.9)\end{array}$ \\
72
\end{tabular}

Table 5: Absolute Revision to Deliberative Ethical Reasoning Scores by Group

\begin{tabular}{|l|l|}
\hline $\begin{array}{l}\text { Majority members-absolute revision } \\
\text { (standard deviation) }\end{array}$ & $\begin{array}{l}10.1 \\
(8.0) \\
72\end{array}$ \\
\hline $\begin{array}{l}\text { Minority members-absolute revision } \\
\text { (standard deviation) }\end{array}$ & $\begin{array}{l}7.7 \\
(7.0) \\
n\end{array}$ \\
\hline t-value for equality of means & 1.14 \\
Significance & 0.13 \\
\hline
\end{tabular}

